\title{
Economy in Study-II
}

\author{
Educative Imagination
}

\section{By Prof. George Van N. Dearborn, A.M., Harvard, MD., Ph.D., Columbia}

\begin{abstract}
In the first article we ran over some of the practical considerations of taking notes, both on the tablets of one's memory (observation) and on tablets of paper, which you will recognize as note-books. How we can practically further the use of these notes, both cerebral and manuscript, in the learning process, is our important next inquiry. This process in practice may be analyzed and understood, and improved in any given mind.
\end{abstract}

Imagination may not be easily defined to you except by suggesting what it is not: It is not falsehood and untruth, but a most essential form of mental truth, and educationally is of very great practical importance. Some of you are wondering how imagination as you think it can be important in learning at all. The reason for this is that a wrong meaning of the term imagination has crept into general untechnical use, namely, that imagination is delusion, a false idea, an error of thinking, the seeing of something that is not there; false perception-in other words, in general, error and falsehood rather than something which is real and in every way important. Imagination, on the other hand, is one of the most productive mental processes in the educational procedure. It is "the representative power" of the mind, but this, as we shall see, involves much, since in a broad sense it includes many of the active constructive operations of the mental life. Dean J. R. Angell, the eminent psychologist of Chicago University, emphasizes the two leading features of imagination when he writes that it "is to be viewe not only as the process whereby the ordinary practical affairs of life are guided, in so far as they require foresight, but also the medium through which most of the world's fine types of happiness are brought to pass." Surely a thing which at once guides our lives and gives us happiness is of much account; and in the learning procedure
it is not of less account. Imagination may be denoted it is not of less account. Imagination may be denoted
as the use of the mind backward or forward, turning the latter into the past or into the future, but not directly into the present. That is one of the most conspicuous aspects of the nature of imagination, but by no means all of them.

Memory is a form of imagination called reproductive imagination. Foresight in a broad sense is another form called the constructive imagination, which, however, we shall discuss in a way to include much more
than this. Influence of the min on the body is called organic imagination. Each form has notable practical concern in learning. Our present search is as to how this fact is so and as to the practical means of developing imagination, if not already ample and rich, in yourselves.

Let us now take up these three kinds of educative imagination, then, and see what we can suggest about them in the way of practical use in easy learning.

I. Reproductive imanination, memory or recall including both moral and mental. There is evidence that the nervous system retains every clear impression made on it, but how long we do not as yet know. A great many cases have occurred from time to time, which demonstrate that this in some way is the case. There are three general types of retention memory that have more or less to do with the reproductive imagination. Some of these "memories" are hereditary, inborn, and are represented in the spinal cord: the reflexes. The sneeze, the cough reflex, etc., are more or less unintentionally performed and controlled. Then there are some memories which are controlle further up in the brain the instincts and emoticns, having social as well as personal reference. It is important for educative purposes that these latter memories involve the previous kind as well. The third type of the reproductive imagination is located in the upper extremity of the nervous system, namely, in the cortex of the brain. These are the latest additions in the evolution of the brain. Memories proper, these are, and only a few of them are conscious at any one time. These last, like the preceding, should completely involve the other two.

The fundamental principle of halit is what determines the usefulness of these forms of memory for easy learning. Their respective power of recall depends on their relative influence on the more conscious parts of the brain. There is, then, one general learning principle, namely, that all these three kinds of memory should be given habitual yet conscious reference, as conscious as is voluntarily possible. Reduce from physiological to practical terms, this means that we come again to the skill that we spoke of last time; conscious acquaintance with all parts of the body that may
properly come (without interference with function) under voluntary control. This is one of the physiologic bases of rapid and permanent acquirement. By thi means every learning pathway is open for use in the acquirements of knowledge. Physical training here gets its highest sanction and usefulness.

The power of recall of what once has been remembered is one of the essential things for learning. The perfection of the memory record is beyond control, but this power of recall may be greatly developed. You must remember all the time that the brain acts more or less on the symbolic system, using a method of shorthand symbols which in some way were impressed in the brain processes; these are essentially integrations. Hence the need of revicuing; in order, namely, that these associations or integration complexes may be more intimately connected together, and with the rest of the mind. Recall is thus made easier and more use ful for facts, and their relations are sorted out and labeled, oftentimes with a name, as with all "genera ideas." By this means they are made far more available for use at will.

Another practical point for the use of the reproductive imagination is that it should be impressed uith feeling of sume sort. It is the emotional tone of nearly everything of a mental nature which gives it its "push" and determines its useful activity. The exact kind of feeling for this purpose is not so important as is the fact that the memory should be associated with some sort of feeling tone. Feeling, and not the idea, is the mind's great energizer. Therefore, in general, one re members best one's pleasant (or very unpleasant) ex the first glance over your memories, but I think that in the long run it is distinctly true. It has recently been shown, in fact by actual experiment, that young schoo girls at least remember their pleasant experiences best In other words, other things being equal, one should study chiefly and should remember those subjects which are pleasing to him. This is one of the reasons for the privilege of selecting subjects of study in school-the sanction of the elective system.

When the reproductive imagination (memory) seems wholly perfect to the individual the experience is calle an hallucination. Thus when one has an hallucination he perceives something which is not really there at all. This happens only under conditions of mental overstrain, or of derangement of some sort. So far as the perfection of recall is concerned it is quite impossible for a really perfect reproduction of the original impression. The moral of this discussion of the imperfection of the imagination is that the memory is neve exact. Recall is never normally exact, and the student must act on this principle in all ways.

But none the less, the reproductive imagination is often of very great service in learning, both in the recal of words seen and heard, etc.; continually, but in picturing to one's self for use the conditions of hidden or absent structures. We have already in our introduction in oth its reproductive and its constructive aspects, is in anatomy, physiology, pathology, medica diagnosis, and so on. The same is almost equally true in many other sciences-in fact, in most branches of learning. The difference, for example, in the liking or dislike of geometry by students depends largely on their relative power of visualizing the spatial problems in volved. One, then, should develop to its limit this poue of seeing things in the mind's eye-and of hearing them, and feeling them and smelling them and tasting them. Thus the material world is, for educative purposes, ex tended in far wider mental relationships than otherwise

II. The second form of imagination that we will discuss is constructive imagination. This is by far the most important of the three for educational purposes. The reason that recall of one's memory is never exact is that the mind is an active process, always doing something. The neurons are alive with energy and always develop their mental contents. Thus all imagination, educationally speaking, is more or less constructive. You have heard it said that one learns to swim out of water in the winter time, or to play tennis; one sometimes learns to love a person better during his absence, which "makes the heart grow fonder." These are all processes of constructive imagination, and in the last case, when you get back to the beloved person you sometimes realize the constructive difference. 'This all, of course, is a subconscious process; but in the human mind imagination has more power than the relatively passive subconscious development.

You have the ability to force the constructive imagination, just as one has the power to work out a line of thought, for example in writing a composition, a essay, a thesis, or a book. All real education is develoled thus, namely, by the unrolling of intelligence out of materials obtained everywhere and all the time, mostly subconsciously. One may have much knowledge and even learning, but not education without this constructive process of imagination. The more conscious this construction, the better and more useful for the student. When conscious this is called thought (technically "ratiocination"), which we shall describe and apply later.

It is interesting to consider a little more in detail the constructive imagination. It is really a very remarkable process which we may try to analyze. There is such a large individual difference in people that it is scarcely possible to find two people who will agree to the same statements as to the facts. But take for example, a musical theme, or a simple melody commonly called a tune; heard once, in my own case, this is not recalled, save in the smallest bits, a bit here or there. But heard twice or more: then three or four wholly silent days elapse, with total submergence, that is, nothing at all is heard from it. Then, curiously enough, it begins to become conscious, now and then a strain here or there in the melody. If then I hum or play a few strains the missing parts, more or less complete, soon appear, but gradually and in fragments, especially if I whistle or play these fragments on some instrument. Performance of some kind is generally essential to recall. You have to push the imagination association. The process is repetition, even to automaticity, even to triteness. If the new tune is attraciive there is a distinct tendency to hum it and sing it until it gets more than tiresome. It has now obviously by this time become a real part of one's mind. It then, Ierhaps more or less actively, sinks into the subeonscious mind, having been repeated until it is positively unpleasant. When a tune has become so familiar on a basis of pleasure, it tends to thus repeat itself even to dismissal.

This may be employed as a useful type of conseiens imagination, and we may suggest more details from this illustration for the process of learning. Let us analyze a little more fully what has taken place in this common experience of learning (by the constructive imagination) an ordinary sequence of musical tones. chosen six more or less obvious, but yet arbitrarily in this process. First there is an imor in the nervous system, as you care to state it. Secondly, we find a process of unconscious integration, in which period (several days in the case I used as an illustration) there is no awareness whatever of what is going on. Third, there is a fragmentary flotation into consciousness, and these fragments are made more conspicuous by use and by repetition. Fourth, there is a process of conscious integration by effort, and this is by far more effective if it be helped by motor performance, such as humming, singing, playing it on some instrument or whistling. Fifth, there is a stage of conscious familiarity, or even of over-familiarity. And sixth, there is a real mental submersion, the melody being there then as real knowledge. Now I take it that all matters of knowledge, all acquirement occurs more or less in the same way, whether the precise learning be the Constitution of the United States of America or the irregular French verbs, the rule for finding the cuberoot, the provoking rules of Latin grammar, a set of propositions in geometry, the physiology of the regulation of the body-heat, the geologic periods, or what not. I take it that the process is always in some degree the same as in the impression and recollection of a new melody. Let us work it out a little better practically. 1. The material to be learne is read through once or twice, but, being relatively difficult, is not consciously learned. The practical point here, if any is at hand, is the importance of concentrated attention on the more difficult and arbitrary material in a subject of study in order to impress the brain all the more vigorously. Retention would often be aided, too, as has been said, by doing this study with some emotional tone, preferably one of determination or enthusiasm; but even anger! 
2. The mind, finding the material and its acquisition expedient, works it over, not only within itself, but more or less also with the former contents of the mind. The practical moral of this interval is obvious: the value of review, which reinforces the impression on the brain. Another moral is peace of mind and alsence of process of the mind.

3. Fragments here and there float into consciousness, so that one is reminded that the mind is working on them, and thus is kept at it

4. At the next attempt at learning (whether it be a few hours away, or a few days) effort is used, what we call conscious study, and we find integration easier than before. Going over the same material to be learned, after a few days, deliberately and carefully once or twice, lends one confidence in one's mind by showing that processes are helping which are unknown to the student at the time.

5. The stint is then learned, and you are conscious of the fact. Here work, and especially motor, expression -work on the material, is very productive, making it thus thoroughly familiar by the instinctive pleasure of creation, of learning, and on the principle of imitation or habituation. The importance of working over th material in some motor way (usually writing it or
talking it to some one, if it be only one's-self) comes out here. Also the importance of repetition.

6. The material is then "forgotten," so-calle forgotten, but in reality is really learned and is in the mine in the best possible form for use as required.

Such are some of the practical hints toward easy learning that may be suggested, even in a process as abstract as the constructive imagination.

This is the standard modus operandi of the learning mind, at least on all series of difficult facts and principles. The less arbitrary and more interesting the material, the easier this mental process is, and the simpler, although the same in principle. This is the process sometimes known as the association of ideas. Try to analyze it a little better in the light of the actual association of the tune.

A practical point may be noted at this point: If the desired thought or relation, or whatever be the kind of association process desired, cannot be produced by a
few minutes of really concentrated effort, it is not scienific to try further at that time without a break in the mental effort. Rather should one await a brain refreshed by a little rest and helped by the subconscious freshed by a little rest and helped by the subconscious
integrative actions that are pretty sure to be set going by the conscious effort already made. When the problem is taken up consciously again, later in the hour or the day or the week, the chance of success, other things equal, will be much improved, and that without risk of uneconomical fatigue. Moreover, there is such a thing as absolute block of the will in this constructive learning-else of course there would not be the empirical definite limitation of ingenuity and invention. Well do I recall an instance in which William James, master in constructive thought, showed just this phenomenon be fore a small class in philosophy - he said, after a minute or two of strenuous effort, that he had "tried his best repeatedly to work out that particular thought, but that he could not advance his construction" beyond a certain relatively incomplete stage.

Imagination of the thinking kind tends to make ideas more "massive," and so more educative. Massiveness makes them easier to realize in their actual meaning, in this case more imaginable.

The next topic in regard to constructive imagination is the matter of complexes of mental units. Knowledge is in the mind in some way in the form of mental in tegrations. Morton Prince termed these "dormant ideas," units in some sense or other not yet clear to physiology. These mental units have dynamic relations which they and the nerve energy have in common, so which they and the nerve energy have in common, so ing tone, have an inherent impulse to interaction.

An effort should be made, then, by the student in all ways to make these complexes, 1 , as numerous; 2 , as complex; 3 , as active; 4 , as perment ; 5 , as generally useful as possible. The process of so making them is effort, and is at once imagination, thought, association and remembering combined. Now one can make these complexes of the mind, these dormant ideas or units of mental process, more, 1, numerous by reading, talking, by taking notes, by observation, by thinking; in short by all the common modes of acquiring new concepts or ideas. 2. One can make them more complex by practically the same means. 3 . One can make them more active $(a)$ by including in the complex an emotion or a feeling, one of the ninety or so of which I have recently published a list and brief discussion. These constructive complexes in the mind may be made more active also by (b) developing interest, instinctive or personal, and $(c)$ by association with material which already has interest or emotional tone for you. William
James has emphasized this essential fact in his valuable "Talks With Teachers." He says that "any object not interesting in itself may become interesting through becoming associated with an object in which an interest already exists." Also by Pavlov and more recently by Watson at Johns Hopkins (as discussed in the previous article) it was found that there is no assignable limit to the arbitrariness of the association that may be "artificially" made in the nervous system. Nerve surgery suggests precisely the same thing, for, as has been often shown in practice, a cut sensory nerve may be sutured even to a motor nerve stump, and the sensory function return in all its essential completeness. There seems to be no end to the power of association possible in the nervous system. 4. Permanency of the mental units or complexes may be reached best by way of $(a)$ emotional tone; (b) by the richness of the recorded relationships; $(c)$ by the intensity of the personal at tention when the perception first takes place; and $(\boldsymbol{d})$
by the frequency of review, among other means. 5. The utility of the mental complexes or units is reache automatically by the mere avoidance of thoughts, etc. of the scholastic type, problems and theories whic have no deeper reality or basis in fact than the chance relationships of pure ideas, verbal quibbles. One shoul for the most part think of and discuss real problem with some really human applications.

Originality, ingenuity, skill are terms for a productive and efficient constructive imagination. One who lack these is not educated. Skill, as we saw in the previou article, is a kind of potential imagination. We may sug gest a working rule for becoming able in this line of constructive imagination, may one be pardoned, in almost slang terms: Get posted; get energetic; get inte ested; get busy; and try. And keep on trying. Tryin in any intelligent mind develops its own personal method, and one cannot be told how to improve these methods in the subconscious mind. Habit makes it ductive as well as easier. Constructing and constructive imagination becomes after a while in itself (some thing which one always has ready in hand) a vast pleasure and delight. Not only in ideation, but in feeling and willing, is the mental activity worth cultivation for its own sake-like virtue and beauty its own reward. Feeling imagination lends emotional tone to the mention, as well as power. This may be seen readily in noetry and in music. We have discussed elsewhere the sthen euphoric index (which is not really so bad as it sounds). It means that you expend more energy in doing things that you enjoy doing than in those that are unpleasant to you. This is of the utmost importance, of course, practically.

Imagination is at once a most practicable and a most valuable educative process. Invention and scientific research would be unproductive without it. One of the greatest pathologists of recent times, Paul Ehrlich, dis coverer of salvarsan, spoke of his chemical imagination as his "greatest asset." Here some of my hearers are suggesting to themselves that the use of the imagination leads to what has been once and forever abandoned out of science and education as the deductive method. But the use of the constructive imagination is not "de-
duction," not a fitting of science to belief or to dogma or to mere opinion, but is rather an elaborate case of the method of trial and error. In using one's imagination scientifically, constructing a theory, one first sees if it fits. If not, he must be willing to throw it aside frankly and promptly; the only danger lies in obstinacy. Examples are innumerable of the great usefulness of this common method of trial and error. The indispensable employment of imagination is shown in the planning of the Atlantic cable, the telegraph, the wireless, the telephone, the electric light, submarines. These and such could not have come into existence without a preliminary use of some one's creative imagination. Theories, hypotheses, philosophies, are all impossible without it. Imagination is at once more useful and more used than is known in education. No knowledge can be made one's very own without this creative process, often called "assimilation" to the contents of one's mind. Summarizing, reviewing, and abstracting is a tive imagination. Better still is the process of using one's memory to the best advantage, thought, thinking things over that you have just learne ; there can be no true education without this process, for it means self-reliance, independence. Thought over a study topic tends, by association, to go beyond the original limits
of the assignment as learned, and this is imagination. of the assignment as learned, and this is imagination and of originality.

The creation of diagrams and illustrations is using the imagination to a very great advantage.

The constructive imagination may be aided and consciously and deliberately developed by the proper mealls.
In childhood, by the reading or hearing of fairy stories, and later on by the reading of books like "The Fairy Land of Science," Thomson's "Wonders of Life," histories of discoveries, Sir Oliver Lodge's presidentia address on continuity, novels like those of Jules Verne or H. G. Wells; talking with fanciful and imaginative persons, and often by an active process of deliberate

Another mode by which the creative imagination may be developed is the enlargement of one's vocabulary, one's list of words, and the habitual use of these idea handles in writing. New terms lead to new associations. In general, as we shall see, the dictionary is not used nearly as much as it should be for easy learning.

III. The third kind of imagination which we mentioned was the organic imagination. This may be termed the influence of the mind over the body, suggestion, and this is a very familiar word to all of you nowadays. This is a very strong and important process in education. Ordinarily one's interests are unrealized and one's capabilities unknown. Millions of indigent and neglected children are thus hadicapped. The playgrounds, camps, etc., develop this knowledge. The basis of organic imagination is strictly physiologic process, and I state each year with more and more emphasis, the result of observation direct and otherwise, that there is no assignable limit to the voluntary control of the body. This matter may be extended to the intellectual subjects of education as well as to bodily education proper.

deas that are inherently meaningful in human reason; or that are massive, full of detail (for example, laboratory work and direct observation); or that are especially striking because of contrast effects or from other conditions, exert the most suggestive influence, and are thus the richest educationally and stimulate the imagination most. None the less the use of the organic imagination in general is perhaps more hygienic and ethical than narrowly educative. But this, too, is education, how to be well and how to be happy. This invaluable part of learning, the organic imagination, however valuable, we must ignore in these discussions. But all the Why Worrybooks, and the New Thought, and Christian Science (its irrationalism aside), all the mindcures and some of the really scientific psycho-therapeutics, are applications of the organizing of the organic imagination. This is a suggestion which is of much value to easy learning.

\section{Business in Engineering}

In an address to the Junior Institution of Engineers, Mr. F. G. Hatch emphasized the importance of the commercial side of engineering from several points of view.

The young engineer too often thinks that all engineering matters should be regarded as having only a re beneath the notice of the engineer. But every engineering undertaking and appliance has to stand a test, not only of its scientific interest or accomplishment, but finally of its practical and commercial value. The ability to judge of this value and turn it to account is an important part of the business of engineering, and this aspect of this work is not sufficiently born in mind, especially by younger members of the profession, or business. It is rarely mentioned by their early teachers and masters, or in the classes of colleges or technical schools. It is no wonder that in view of the fact that engineering students receive no regular business training, engineers as a whole are poor business men. It of the general principles of engineering to enable him to control a works than it is for the engineer to get into business ways when time and advancement make it necessary for him to do so.

There is undoubtedly among all technical men a feeling of contempt for financial results. They feel their existence and position is justified when whatever mawears well. If it does not sell well or bring the desired financial results, this side of the question is dismissed without further thought than that it is a pity; but from their (the technical) point of view, virtue is its own reward, and in any case it is "up to" the commercial side to look after this side of the business. They, as engineers, cannot soil their hands or occupy their minds with any sordid commercial considerations. The commercial side, finding that they, and they alone, have to bear all the burdens of financial success, set themselves to obtain the desired results with very scant sympathy for technical considerations. Thus it is brought about that the technical men do not have much influence in controlling the policy and affairs of their firm, because too often they have failed to get those results which are the only final interest of directors and shareholders.-From an address to the Junior Institute of Engineers (England) by F. G. Hatch. 